\title{
RESISTANCE OF CARICA CANDAMARCENSIS TO THE MOSAIC VIRUSES AFFECTING PAPAYAS (CARICA PAPAYA) IN PUERTO RICO
}

Viruses causing papaya mosaic seriously limit production of papayas in Puerto Rico. ${ }^{1,2}$ These apparently are spread by insects. All efforts have failed to control spread of the disease thus far in the field by insecticides. Resistance to these viruses has not been found among papayas tested at the Agricultural Experiment Station.

This note reports evidence that Carica candamarcensis, a South American species of papaya native to the Andean hills of Venezuela, Colombia, Peru and Chile, is highly resistant to viruses responsible for papaya mosaic in Puerto Rico. This species is said to produce small fruit of outstanding qualities.

A series of about 40 seedlings, obtained from Chilean seeds through the courtesy of Mr. John D. Gotston, Consultant of the Puerto Rico Industrial Development Co., were grown at the Experiment Station. They were inoculated twice at one-month intervals with juice obtained from $C$. papaya exhibiting clear-cut symptoms of papaya mosaic. Healthy but susceptible $C$. papaya plants were inoculated simultaneously with the same juice. Some of the inoculated C. candamarcensis had been grafted previously on $C$. papaya stocks to avoid foot rot disease to which $C$. candamarcensis is reported susceptible.

None of the $C$. candamarcensis plants inoculated with the mosaic viruses present in Puerto Rico exhibited symptoms of the mosaic disease after several months of observation. All the inoculated $C$. papaya controls became infected in about 10 to 12 days. Repeated attempts were unsuccessful to recover the viruses from the inoculated $C$. candamarcensis plants.

To test further the apparent resistance of $C$. candamarcensis to our local papaya mosaic viruses, plants of $C$. papaya previously inoculated and clearly showing symptoms of mosaic were topped and cleft-grafted with healthy $C$. candamarcensis scions. Some of the grafted scions died but those that were successful did not develop symptoms. No symptoms developed when juice extracted from leaves of these apparently healthy grafted $C$. candamarcensis plants was inoculated to healthy susceptible papaya plants, indicating absence of virus in leaf tissues.

According to Jiménez and Horovitz, ${ }^{8}$ C. candamarcensis can be crossed

1 Adsuar, J., Studies on virus diseases of papaya (Carica papaya) in Puerto Rico. I. Transmission of papaya mosaic. II. Transmission of papaya mosaic by the citrus aphid (Aphis spiraecola Patch). III. Property studies of papaya mosaic virus, $J$. Agr. Univ. P. R. 81 (3): 248-64, 1947.

'Adsuar, J., A new virus disease of papaya in Puerto Rico. (In preparation.)

8 Jiménez, H. and Horovitz, S., Cruzabilidad entre especies de Carica, Agronomia Tropical 7 (4): 207-15, 1958. 
with C. papaya, although seed fails to mature. In most cases, however, the immature embryos can be cultivated successfully.

Plants of $C$. candamarcensis taken to our Substation at Limani, Adjuntas, at an altitude of about 1,800 feet were observed to thrive, blossom and set fruit. This mosaic-resistant species of papaya apparently could be grown successfully under our conditions. 